\title{
BIOÉTICA DAS INSTITUIÇÕES PIONEIRAS - PERSPECTIVAS NASCENTES AOS DESAFIOS DA CONTEMPORANEIDADE
}

\section{Bioethics of the pioneer institutions - rising perspectives connected to the challenges of contemporary}

\author{
Leo Pessini \\ Centro Universitário São Camilo, São Paulo, Brasil. \\ pessini@scamilo.edu.br
}

Resumo: Este artigo divide-se em duas seções que serão apresentadas sequencialmente aqui e no próximo volume da RBB. Nesta primeira seção analisase o pioneirismo de Van Rensselaer Potter, conhecendo a pessoa, seu legado intelectual, sua concepção de ciência e religião juntas com o objetivo de garantir o futuro da vida no planeta terra, o seu credo bioético e uma apreciação crítica de sua obra a partir de dois de seus discípulos, Gerald M. Lower e Peter J. Whitehouse.

Palavras-chave: Bioética. Ciência. Religião. Ecologia.

\begin{abstract}
This article is divided in two sessions that will be presented here and in the next volume of RBB. In the first one, the pioneeiring work of Van Renselaer Potter is analised, considering to some important aspects of his personal history and outstanding academic work. One special issue is the discusson on the relation between science and religion in the quest for global survival of humankind and bioesfere. Potter's bioethical creed for individuals is presented as well as an critical apraisal from two of Potter's followers, Gerald M. Lower e Peter W. Whitehouse.
\end{abstract}

Key words: Bioethics. Science. Religion. Ecology. 
bioética consolidou-se com uma espetacular história de sucesso, especialmente quando se considera seu pouco tempo de existência. Há apenas 35 anos do surgimento do neologismo bioethics, pela intuição de Van Renselaer Potter e pouco mais de duas décadas da fundação dos primeiros institutos de bioética estadunidense - o Kennedy Institute em Washington e o Hastings Center em Nova York - é utilizada em todo mundo, conquistando adeptos e o respeito de eminentes estudiosos.

Após o estabelecimento de inúmeros institutos e programas em universidades em todo o mundo, estamos entrando em nova fase, com a implantação dos primeiros mestrados e doutorados na área. Fazer uma prospecção do futuro relacionando-a às origens da bioética é o desafio enfrentado neste texto. Dividido em duas partes, iniciamos com o resgate da figura pioneira de Potter, apresentando a pessoa, seu legado intelectual, o credo bioético potteriano, além da apreciação crítica de dois de seus discípulos, Gerald Lower e Peter J. Whitehouse. Na segunda parte do texto, que será apresentada no próximo volume, discorreremos sobre a Enciclopédia de Bioética (Encyclopedia of Bioethics), obra fundamental e referencial da bioética nascente e contemporânea, comentando sua concepção, sua evolução ao longo do tempo nas três edições de 1978, 1995 e 2004. Traçaremos uma caminhada com o idealizador e editor-chefe das duas primeiras edições, Warren Thomas Reich, da Universidadee de Georgetown, conferindo atenção especial à última edição da Enciclopédia, levantando com seu editor-chefe, Stephen Post, algumas das questões candentes da bioética atual.

\section{O Pioneirismo de Potter}

\section{Conhecendo a pessoa}

Nascido no Estado da Dakota do Sul em 27 de agosto de 1911, Potter faleceu em 6 de setembro de 2001, em Madison, pequena cidade do Estado de Wisconsin, no meio-oeste dos Estados Unidos, ao completar 90 anos, deixando esposa, três filhos, seis netos e duas irmãs.

De seu avô, que morreu de câncer um ano antes de seu nascimento, aos 51 anos, herdou o nome, vindo a se chamar Van Rensselaer Potter II. Desde a morte de sua mãe em um acidente de carro quando tinha sete anos de idade, Potter passou a ser muito ligado ao pai.

Por ocasião de seu falecimento recebemos um comunicado de sua neta Lisa Potter, que trabalhou muito perto do avô, entre 1994-1997, 
auxiliando-o nas publicações de bioética e em conferências. Nesse comunicado ela relata:

"Lamentamos informar que Van faleceu ontem (6/09) às 5h20 da tarde. Ele estava confortável e a família mantinha-se presente ao lado do leito. Eu segurava sua mão quando exalou o último suspiro. Sei que ele sentiu o apoio e amor da família. Ele morreu logo após seu $90^{\circ}$ aniversário e teve a chance de ver muitos membros da família. Sentiremos muito sua falta".

Como é amplamente conhecido, foi Potter quem cunhou o neologismo bioethics em 1970. Entretanto, chamá-lo de "pai da bioética", como muitos fazem, seria um exagero, segundo alguns críticos, estudiosos da história da bioética. Não obstante, dizer que ele é somente autor do neologismo que batizou esse campo de estudo não seria uma afirmação justa, especialmente quando se considera sua envergadura moral, sua dedicação como pesquisador e pioneiro da bioética.

Poucos dias antes de seu falecimento Potter deixou uma mensagem final, endereçada aos amigos da sua "rede de bioética global". Nesta mensagem demonstra ressentimento pelo não reconhecimento de seu trabalho em bioética em seu próprio país:

"Por um longo período de tempo, 1980-1990, ninguém reconheceu meu nome e quis ser parte de uma missão. Nos EUA houve uma explosão imediata do uso da palavra bioethics pelos médicos, que falharam ao não mencionar meu nome ou o título das minhas quatro publicações de 1970-1971. Infelizmente, a sua imagem da bioética atrasou o surgimento do que existe hoje". (HARVARDSQUARELIBRAY, 2004).

A biografia de Potter é particularmente relevante para a história de uma idéia - o conceito de autonomia - que desempenha até hoje papel predominante na ética biomédica norte-americana. De acordo com essa visão, que pautou seu comportamento pessoal e profissional, antes de enfocar direitos individuais deve-se enfatizar responsabilidades pessoais. Seguindo fielmente essa assertiva, Potter não só elaborou, mas viveu seu credo de ativista, formulado a partir da responsabilidade social e ambiental. Como bioeticista virtuoso que foi, não apenas viveu sua visão de bioética, como também conclamou outros a fazê-lo, alertando que, para merecer ser chamado de bioeticista se deve seguir tal credo, que apresentaremos na íntegra neste 
texto. A forte ênfase na ética das virtudes destaca-se na bioética potteriana, que adquire um tom quase de pregação.

Potter era considerado um distinto membro da Sociedade Unitariana de Madison (Unitarian Society of Madison), organização de inspiração cristã que segue o espírito de Jesus de Nazaré e defende a perspectiva de uma religião liberal. Trata-se de uma associação aberta, em que o ateu honesto pode se declarar como tal, sem nenhum medo, bem como o crente piedoso falar de sua ligação pessoal com o universo e com Deus sem embaraço. Os unitarianos constituem-se uma confraria de livre pensamento em que são aceitos como membros “... pessoas de todas as opiniões teológicas, que desejam se unir a nós na promoção da verdade, justiça, reverencia e caridade entre os homens" (HARVARDSQUARELIBRAY, Op. Cit.). Entre os objetivos dessa organização, destaca-se o primeiro, que diz respeito à integridade de vida, que significa a totalidade (wholeness). Para as pessoas de genuína integridade, todos os objetivos e questões de vida estão interrelacionados.

Na página virtual desse grupo lê-se textualmente: “... a única exigência que fazemos e que esperamos é que sejamos honestos conosco mesmos e com os outros" (HARVARDSQUARELIBRAY, Op. cit.). Embora não haja nenhuma menção à ligação entre a visão de Potter e a organização dos unitarianos, é perceptível a profunda associação entre o credo bioético potteriano e a filosofia dessa organização.

Potter doutorou-se em bioquímica e trabalhou mais de 50 anos na Universidade de Wisconsin, nos Laboratórios MacArdle para a pesquisa de câncer, aposentando-se em 1982. Sua contribuição original sobre a compreensão do metabolismo das células cancerígenas foi reconhecida, contribuindo para sua eleição para a Academia Nacional de Ciências. Foi presidente da Sociedade Americana de Pesquisa sobre o Câncer em 1974, além de ter atuado em inúmeras outras organizações científicas de grande prestígio nos EUA.

Após sua aposentadoria, Potter praticamente passou a residir em sua casa de campo, localizada em meio a um bosque, nas cercanias de Madison. Ali recebia amigos e estudantes na varanda de madeira rústica, sentindo-se em comunhão com a natureza. Nos últimos anos de vida, dedicou-se ao cuidado de sua esposa, Vivian, tragicamente deficiente em decorrência de artrite. Por opção, deixa de viajar e dar conferências pelo mundo afora, ficando junto a sua companheira.

A última viagem que realizou ao exterior foi em 1990 para a Itália, a convite de Bruneto Chiarelli, professor de antropologia da Universidade de 
Florença, quando falou sobre Bioética Global. Estava com 79 anos, e quase não mais viajava, embora recebesse inúmeros convites para participar de eventos de bioética, para os quais enviava vídeos de suas três palestras: palestra sobre Bioética Global, em 1998, por ocasião do IV Congresso Mundial de Bioética, em Tóquio a convite de Hyakuday Sakamoto; palestra para o Congresso Mexicano de Bioética, em 1999, a convite do falecido Manuel Velasco Suarez; e palestra para o Congresso Internacional de Bioética, em 2000, organizado pela Sociedade Internacional de Bioética (SIBI) na Espanha, a convite de Marcelo Palácios.

Uma resolução elaborada pelo corpo docente da Universidade de Wisconsin em memória de Potter destaca a importância de sua vida profissional como pesquisador e professor de oncologia no Laborátório McArdle de Pesquisa de Câncer, durante mais de 50 anos, e enfatiza a importância da fase final de sua vida, justamente os últimos 30 anos dedicados à bioética:

“...sua maior contribuição para a comunidade científica são os mais de 90 doutorados que orientou e estudantes de graduação que inspirandose nele, muitos tornaram-se proeminentes em vários campos da ciência, sendo que um deles foi agraciado com o Prêmio Nobel. (....) Para Van a ciência, não era um 'trabalho' mas, uma experiência ética, apaixonada e criativa. Além do mais, ele não separava o cientista do processo científico ou o cientista do contexto social do empreendimento científico. Esta filosofia, motivado pelo seu conceito de 'humildade com responsabilidade', o conduziu à fase final de sua produtiva carreira" (MCARDLE, 2002).

Potter é lembrado por seus colegas de docência na universidade como "um ser humano iluminado, preocupado com o cuidado humano de tudo, para que todos pudessem viver, não numa utopia, mas em um mundo esteticamente belo e sustentável, uma vida satisfatória e feliz" (MCARDLE, Op. cit).

\section{O legado intelectual}

Potter, que chamou a bioética de "ciência da sobrevivência humana", traçou uma agenda de trabalho para a mesma que vai desde a intuição da criação do neologismo em 1970, até a possibilidade de encarar a bioética como uma disciplina sistêmica ou profunda em 1988. É interessante recordar 
alguns momentos mais importantes deste itinerário, iniciando pela história do surgimento do neologismo bioética (POTTER, 1971).

Nos anos 1970-71, Potter cunha o neologismo bioethics, utilizando-o em dois trabalhos: no artigo Bioethics, science of survival, e no livro Bioethics: bridge to the future. Esta publicação é dedicada a Aldo Leopold, renomado professor na Universidade de Wisconsin, que pioneiramente começou a discutir uma "ética da terra". O termo apareceu na mídia em abril de 1971 quando a Revista Time publicou um longo artigo entitulado "Man into superman: the promisse and peril of the new genetics", citando o livro de Potter.

No termo bioética (do grego bios = vida e ethos $=$ ética) o primeiro refere-se ao conhecimento biológico, a ciência dos sistemas vivos, e o segundo relaciona-se ao conhecimento dos valores humanos. Potter almejava criar uma nova disciplina que propiciasse uma verdadeira e dinâmica interação entre o ser humano e o meio ambiente, perseguindo a intuição de Leopold e antecipando-se ao que hoje se tornou uma preocupação mundial, que é a ecologia. Na contracapa de Bioethics: bridge to the future, ele destaca:

"Ar e água poluída, explosão populacional, ecologia, conservação - muitas vozes falam, muitas definições são dadas. Quem está certo? As idéias se entrecruzam e existem argumentos conflitivos que confundem as questões e atrasam a ação. Qual é a resposta? O homem realmente está colocando em risco o seu meio ambiente? Não seria necessário aprimorar as condições que ele criou? A ameaça de sobrevivência é real ou se trata de pura propaganda de alguns teóricos histéricos?" (POTTER, Op. cit.).

“...Esta nova ciência, bioethics, combina o trabalho dos humanistas e cientistas, cujos objetivos são sabedoria e conhecimento. A sabedoria é definida como o conhecimento de como usar o conhecimento para o bem social. A busca de sabedoria tem uma nova orientação porque a sobrevivência do homem está em jogo. Os valores éticos devem ser testados em termos de futuro e não podem ser divorciados dos fatos biológicos. Ações que diminuem as chances de sobrevivência humana são imorais e devem ser julgadas em termos do conhecimento disponível e no monitoramento de 'parâmetros de sobrevivência' que são escolhidos pelos cientistas e humanistas" (POTTER, Op. cit.).

Potter pensa a bioética como uma ponte entre a ciência biológica e a ética. Sua intuição consistiu em pensar que a sobrevivência de grande parte 
da espécie humana, numa civilização decente e sustentável, dependia do desenvolvimento e manutenção de um sistema ético. A respeito, afirma na introdução daquele livro:

"Se existem duas culturas que parecem incapazes de dialogar - as ciências e humanidades - e se isto se apresenta como uma razão pela qual o futuro se apresenta duvidoso, então, possivelmente, poderíamos construir uma ponte para o futuro, construindo a bioética como uma ponte entre as duas culturas" (POTTER, Op. cit.).

Anos depois, em 1998, ratificando suas convicções, Potter relata:

"O que me interessava naquele momento, quando tinha 51 anos, era o questionamento do progresso e para onde estavam levando a cultura ocidental todos os avanços materialistas próprios da ciência e da tecnologia. Expressei minhas idéias do que, segundo meu ponto de vista, se transformou na missão da bioética: uma tentativa de responder à pergunta frente à humanidade: que tipo de futuro teremos? E temos alguma opção? Por conseguinte a bioética transformou-se numa visão que exigia uma disciplina que guiasse a humanidade como uma 'ponte para o futuro'" (POTTER, 1998).

É importante registrar que existe outro pesquisador que reivindica a paternidade do termo bioética. É o obstetra holandês, André Hellegers, da Universidade de Georgetown, que seis meses após a aparição do livro de Potter utiliza esta expressão no nome do novo centro de estudos: Joseph and Rose Kennedy Institute for the Study of Human Reproduction and Bioethics. Hoje esse centro é conhecido simplesmente como Instituto Kennedy de Bioética. No Instituto Kennedy, Hellegers conduziu um grupo de discussão de médicos e teólogos (protestantes e católicos) que viam com preocupação crítica o progresso médico e tecnológico, os quais apresentavam enormes e intrincados desafios aos sistemas éticos do mundo ocidental. Para Warren Thomas Reich, historiador da bioética e organizador das duas primeiras edições da Enciclopédia, o legado de Hellegers está no fato deste entender sua missão em relação à bioética como "uma pessoa ponte entre a medicina, a filosofia e a ética". Este legado é o que acabou conquistando maior notoriedade, tornando-se hegemônico, fazendo da bioética um "estudo revitalizador da ética médica" (REICH, 1995). 
Potter não deixou de expressar sua decepção em relação ao curso que a bioética seguiu. Reconheceu a importância da perspectiva de Georgetown, porém afirmou que "minha própria visão da bioética exige uma visão muito mais ampla". Pretendia que a bioética fosse uma combinação de conhecimento científico e filosófico e não, simplesmente, um ramo da ética aplicada, como foi entendida em relação à medicina. Seja como for, fica claro que desde o momento de seu nascimento, a bioética tem dupla paternidade e duplo enfoque, apontando perspectivas distintas: os problemas da macrobioética, com inspiração na perspectiva de Potter; e, os conflitos da microbioética, ou bioética clínica, com clara inspiração no legado de Hellegers.

Em 1988 Potter amplia sua visão da bioética em relação a outras disciplinas, não somente como ponte entre a biologia e a ética, mas alçandoa à dimensão de uma Ética Global:

"A teoria original da bioética era a intuição da sobrevivência da espécie humana, numa forma decente e sustentável de civilização, exigindo o desenvolvimento e manutenção de um sistema de ética. Tal sistema (a implementação da bioética ponte) é a Bioética Global, fundamentada em intuições e reflexões fundamentadas no conhecimento empírico proveniente de todas as ciências, porém, em especial do conhecimento biológico... $\mathrm{Na}$ atualidade este sistema ético proposto segue sendo o núcleo da bioética ponte com sua extensão para a Bioética Global, o que exigiu o encontro da ética médica com a ética do meio ambiente numa escala mundial para preservar a sobrevivência humana" (POTTER,1988).

Em suas palavras finais no vídeo apresentado em Tóquio no IV Congresso Mundial de Bioética, traça a agenda dos desafios futuros da bioética:

"À medida que chego ao ocaso de minha experiência sinto que a bioética ponte, a bioética profunda e a Bioética Global, alcançaram o umbral de um novo dia que foi muito além daquilo que eu imaginei. Sem dúvida, necessitamos recordar a mensagem do ano de 1975 que enfatiza a humildade com responsabilidade com uma bioética básica, que logicamente segue da aceitação de que os fatos probabilísticos, ou em parte a sorte, têm conseqüências nos seres humanos e nos sistemas viventes. A humildade é a conseqüência característica que assume o 'posso estar equivocado', e exige a responsabilidade de aprender da experiência e do conhecimento disponível. Concluindo, o que lhes peço é 
que pensem a bioética como uma nova ética científica que combina a humildade, responsabilidade e competência, numa perspectiva interdisciplinar e intercultural e que potencializa o sentido de humanidade" (CONGRESSO MUNDIAL DE BIOÉTICA. 4, 1998).

Naquela mesma palestra fala também de Hans Küng, célebre teólogo católico, mundialmente conhecido, da Universidade de Tubinguen, na Alemanha, lembrando que este já havia chamado atenção para uma ética global, voltada à política e economia, em relação a qual todas as nações e povos das mais diferentes tradições culturais e crenças deveriam se responsabilizar. Ressalta que o coração da ética global de Küng está no humano, o que lhe parece louvável, e que, embora essa ética global não seja bioética, seus preceitos básicos parecem totalmente aceitáveis, podendo ser seguidos por todos. Sublinha, porém, que esta perspectiva não é suficiente, pois é preciso explicitar o respeito pela natureza e pelas diferentes culturas, para além das culturas judaica e cristã.

Em 1998, Potter expõe a idéia da Bioética Profunda, retomando o pensamento de Whitehouse, da Universidade de Cleveland. O trabalho de Whitehouse incorporou os avanços da biologia evolutiva, em especial o pensamento sistêmico e complexo que comporta os sistemas biológicos. A Bioética Profunda pretende entender o planeta como locus de grandes sistemas biológicos entrelaçados e interdependentes, cujo centro já não corresponde ao homem, como em épocas anteriores, mas à própria vida, sendo o homem somente um pequeno elo nesta grande rede.

\section{Ciência e religião juntas frente ao desafio ético de garantir o futuro da vida}

Em artigo publicado na revista The Scientist com o sugestivo título $A$ ciência e a religião devem partilhar da mesma busca em relação à sobrevivência global Potter afirma que não podemos mais ficar confortáveis com a idéia de que no futuro - se as coisas piorarem - a ciência terá as respostas. Para ele o momento de agir e provar nossa competência ética, bem como técnica, é agora:

“Uma questão central para os nossos esforços deve ser a promoção do diálogo entre a ciência e a religião em relação à sobrevivência humana e 
da biosfera. Durante séculos, a questão dos valores humanos foi considerada como estando para além do campo científico e propriedade exclusiva dos teólogos e filósofos seculares. Hoje devemos sublinhar que os cientistas, não somente têm valores transcendentes, mas também os valores que estão embutidas no ethos científico, necessitam ser integrados com aqueles da religião e filosofia para facilitar processos políticos benéficos para a saúde global do meio ambiente" (POTTER, 1994).

$\mathrm{Na}$ busca de companheiros para a causa, registra que muitos livros e artigos abordam os problemas do meio ambiente e saúde humana, mas relativamente poucos enfocam a questão da sobrevivência da espécie humana no futuro. Entre estes destaca a obra de Hans Jonas, The imperative of responsibility: in search of an ethic for the technological age; a do sociólgo Manfred Stanley, The technological conscience: survival and dignity in an age of expertise; e a Declaração para uma Ética Global do já citado Küng, mentor e redator documento final, apresentado no Parlamento Mundial das Religiões, que se reuniu em Chicago em 1993 (KÜNG \& SCHMIDT, 1998).

É sobre este último que Potter tece comentários, relativos à construção da ponte entre ciência e religião. Criticando a perspectiva da Ética Global de Küng, afirma que no cerne da moral religiosa por este defendida não está incorporada a preocupação com o rápido crescimento populacional. Destaca que dentre os seguidores das maiores religiões mundiais, em particular o catolicismo e o islamismo, estão as populações que mais contribuem para a atual e assustadora taxa de crescimento populacional.

Segundo Potter, somente a ciência tem as técnicas para analisar mudanças populacionais e seu impacto. Ao formular sua Ética Global, Küng apontou uma questão chave para a sobrevivência humana, idéia que nenhum outro teólogo até então sequer tinha mencionado. Embora outros líderes religiosos tenham proclamado que a vida é sagrada e defendido os direitos humanos, somente Küng colocou a sobrevivência humana na agenda da reflexão ética. Os cientistas, por sua vez, há muito tempo abraçaram o desafio do bem estar humano e implicitamente a sobrevivência humana; portanto, estão credenciados para colaborar na causa pela sobrevivência humana e da biosfera.

Potter vai além ao dizer que não somente os teólogos, mas também os filósofos seculares falharam em pensar sobre a sobrevivência humana e da biosfera como uma questão ética. Restritas a relações interpessoais ou sociais entre os humanos, tais reflexões excluíram questões que para ele são fundamentais, relacionadas ao crescimento populacional e aos problemas 
ecológicos. Como ponto importante da famosa Declaração sobre Ética Global Potter destaca: não pode haver sobrevivência sem uma ética mundial, e não existirá paz mundial sem a paz entre as religiões e uma aliança entre crentes e não-crentes (ateus, agnósticos e outros) respeitando-se mutuamente, pode também ser necessária para a concretização de uma ética mundial comum a todos os humanos. A respeito enfatiza:

"Os cientistas devem aplaudir os esforços de Hans Küng ao apontar para construção de uma aliança reconciliatória entre crentes e aqueles que não são fundamentalmente caracterizados como religiosos, incluindo entre estes, penso, a maioria dos cientistas. Precisamos unir as forças frente à responsabilidade global da sobrevivência humana e seu apelo pelo 'respeito mútuo', é necessário para uma ética mundial comum" (POTTER, Op. cit.).

Em vários trabalhos Potter manifesta profunda preocupação com o rápido crescimento da população mundial, lembrando que os demógrafos projetam a duplicação da população em meados do século XXI. A abordagem desta questão revela seu lado de militante obcecado com a questão populacional, que não deixa de ter um viés um tanto alarmista. Suas constantes assertivas no sentido de interromper o crescimento populacional, tornam-se ironicamente visíveis na placa de seu velho carro, YES ZPG (Zero Population Growth), que significa "Sim, crescimento populacional zero" (WHITEHOUSE, 2001). Sabe-se hoje, que a questão demográfica tem uma série de novos fatores, cruciais e preocupantes, que Potter sequer mencionou.

No seu credo bioético Potter explicita que o compromisso em relação à saúde pessoal e familiar se expressa no sentido de limitar os poderes reprodutivos de acordo com objetivos, nacionais e internacionais. Pensando que o problema da superpopulação não pode ser resolvido enquanto as maiores religiões se opuserem a qualquer tentativa de limitar a fertilidade, deixa claro que o diálogo entre ciência e religião não é fácil. Tal constatação gera o questionamento sobre a possibilidade de construir um consenso sobre o assunto e a aceitação dessa diretriz política pelos governos: a busca por uma ética mundial, partilhada tanto pela religião como pela ciência não poderia ser expressa em princípios concretos para a ação? Para ele a inquietação angustiante desta busca permanece sem resposta, pois não há certeza de que se possa encontrar solução satisfatória para tais questões, ao menos no presente momento histórico. 
Sintetizando as questões chave do diálogo entre ciência e religião, vale destacar o que Potter diz a propósito da Declaração das Religiões sobre uma Ética Global:

"Estamos conscientes de que as religiões não podem resolver os problemas econômicos, políticos e sociais da terra. Contudo, elas podem prover o que não podemos conseguir através dos planos econômicos, programas políticos e regulamentações legais. As religiões podem causar mudanças na orientação interior, na mentalidade, nos corações das pessoas e levá-las para uma 'conversão' de um 'falso caminho' para uma nova orientação de vida. As religiões contudo, são capazes de dar às pessoas um horizonte de sentido para suas vidas e um lar espiritual. Certamente as religiões podem agir com credibilidade somente quando eliminarem os conflitos que surgem entre elas mesmas e desmantelarem imagens hostis e preconceitos, medos e desconfiança mútuas" (POTTER, Op. cit.).

Esse trecho demonstra a profunda compreensão de Potter em relação à ciência e à religião, apontando um caminho para aplacar a longa batalha histórica que travam pela hegemonia sobre a verdade. Cada uma delas, quando em posição hegemônica, tenta negar a outra, restringindo a possibilidade dos seres humanos alcançarem verdadeira compreensão (PETERS \& NENNETT, 2003). A visão de Potter, à qual fazemos coro, mostra que agora ambas precisam caminhar juntas, de mãos dadas, em função de um objetivo maior, uma causa que interessa a toda a humanidade: garantir o futuro da vida, humana e cósmico-ecológica, no planeta terra.

Nesse sentido, um dos documentos mais reveladores da personalidade e das convicções de Potter, que fez da bioética sua causa de vida, se expressa no chamado credo bioético.

\section{O credo bioético de Potter}

1. Creio na necessidade de uma ação terapêutica imediata para melhorar este mundo afligido por uma grave crise ambiental e religiosa.

Compromisso: Trabalharei com os outros para aperfeiçoar a formulação de minhas crenças, desenvolver credos adicionais e procurar um movimento mundial que torne possível a sobrevivência e o aprimoramento do 
desenvolvimento da espécie humana em harmonia com o meio ambiente natural e com toda a humanidade.

2. Creio que a sobrevivência futura bem como o desenvolvimento da humanidade, tanto cultural quanto biológico, é fortemente condicionado pelas ações do presente e planos que afetam o meio ambiente.

Compromisso: Tentarei adaptar um estilo de vida e influenciar o estilo de vida dos outros, bem como ser promotor para um mundo melhor para as futuras gerações da espécie humana, e tentarei evitar ações que coloquem em risco seu futuro, ao ignorar o papel do meio ambiente natural na produção de alimentação e fibras.

3. Creio na unicidade de cada pessoa e na sua necessidade instintiva de contribuir para o aprimoramento de uma unidade maior da sociedade, de forma que seja compatível em longo prazo com as necessidades da sociedade.

Compromisso: Ouvirei os pontos de vistas dos outros, sejam estes de uma minoria ou de uma maioria, e reconhecerei o papel do compromisso emocional em produzir uma ação efetiva.

4. Creio na inevitabilidade do sofrimento humano que resulta da desordem natural das criaturas biológicas e do mundo físico, mas não aceito passivamente o sofrimento que é resultado do tratamento desumano de pessoas ou grupos.

Compromisso: Enfrentarei meus próprios problemas com dignidade e coragem. Assistirei aos outros na sua aflição e trabalharei com o objetivo de eliminar todo sofrimento desnecessário à humanidade.

5. Creio na finalidade da morte como uma parte necessária da vida. Afirmo minha veneração pela vida, creio na necessidade de fraternidade agora, e que também que tenho uma obrigação para com as futuras gerações da espécie humana.

Compromisso: Viverei de uma forma tal que será benéfica para as vidas de meus companheiros humanos de hoje e do futuro, e que serei lembrado com carinho pelos meus entes queridos.

6. Creio que a sociedade entrará em colapso se o ecossistema for danificado irreparavelmente, a não ser que se controle mundialmente a fertilidade humana, devido ao aumento concomitante na competência de seus membros para compreender e manter a saúde humana.

Compromisso: Aperfeiçoarei as habilidades ou um talento profissional que contribuirão para a sobrevivência e aprimoramento da sociedade e manutenção de um ecossistema saudável. Ajudarei os outros no desenvolvimento de seus talentos potenciais, mas ao mesmo tempo cultivando o autocuidado, auto-estima e valor pessoal. 
7. Creio que cada pessoa adulta tem uma responsabilidade pessoal em relação à sua saúde, bem como, uma responsabilidade para o desenvolvimento desta dimensão da personalidade em sua descendência.

Compromisso: Esforçar-me-ei por colocar em prática as obrigações descritas como compromisso bioético para a saúde pessoal e familiar. Limitarei meus poderes reprodutivos de acordo com objetivos, nacionais ou internacionais.

\section{Apreciação Crítica da Obra de Potter}

Gerald M. Lower Jr., um dos estudantes que completava seu doutorado nos Laboratórios McArdle quando Potter publicou seu livro pioneiro, observa o seguinte: "Naquele momento, Potter não estava imune da crítica dos pesquisadores locais por se aventurar numa área de filosofia e ética e não em seu laboratório" (LOWER, 2002). O que os críticos de seu trabalho viram como erro, justificando seu não envolvimento público, Lower viu como sendo uma profunda e significativa contribuição.

Lower relata que o termo bioethics foi rapidamente assumido pela comunidade médica, como um rótulo para seu esforço de estabelecer padrões éticos para o exercício de uma medicina de alta tecnologia. Programas de bioética emergiram em muitas partes dos EUA e o neologismo popularizouse, sem que se mencionasse Potter ou sua publicação. Para tornar essa situação pior, o tipo de bioética promovida nos EUA, de cunho pragmático e não conceitual, realmente não tinha nenhuma relação com a vertente potteriana.

Também Peter J. Whitehouse reconhece a pouca relação entre as duas maneiras de conceituar o termo bioethics. Para esse autor o conceito de bioética de Potter não influenciou o desenvolvimento da ética biomédica porque, desde o início, a identificação da palavra bioethics com o Instituto Kennedy inclinou seu uso à medicina clínica.

Segundo esse autor, nos anos 1970 as pessoas estavam preocupadas com as implicações da tecnologia médica, particularmente tecnologia reprodutiva. Este enfoque das implicações éticas relacionadas às descobertas médicas sobre os valores humanos continua dominante na ética biomédica. A trágica falta de preocupação do sistema de saúde relacionado com a saúde pública e meio ambiente pode estar associada com as mesmas forças sociais que levaram Potter a não considerar na sua visão de bioética, questões de medicina de alta tecnologia, medicina genética, orientada pelas forças do mercado.

Fazendo uma crítica dessa vertente da bioética elaborada em seu próprio país, Whitehouse afirma: 
"À medida que a população mundial cresce, as espécies animais continuam a ser eliminadas e preocupações com meio ambiente saudável toma cada vez mais vulto, o que provavelmente faz com que a perspectiva potteriana de bioética ganhe maior proeminência. Por outro lado, preocupações com a profissionalização da ética em torno de certos conceitos limitados de ética médica também continuarão. O enfoque sobre a autonomia individual, como um princípio ético dominante nos EUA, deve mudar para questões mais amplas, de responsabilidade comunitária e de cuidado com o meio ambiente" (WHITEHOUSE, 2003).

Buscando resgatar a memória intelectual de Potter e reafirmar sua legitimidade como autor do termo bioethics, Whitehouse afirma logo no início de seu artigo: "Van Rensselaer Potter foi a primeira voz a emitir a palavra bioethics, mas ele é muito pouco apreciado pela comunidade bioética" (WHITEHOUSE, Op. cit.).

Segundo este autor a maior contribuição de Potter deu-se no sentido conceitual e não factual, influenciando a maneira como vemos e pensamos as coisas e o mundo. Potter estava essencialmente preocupado com o desenvolvimento de uma ética que pudesse guiar o comportamento para permitir a sobrevivência da humanidade e de outras espécies. A bioética de Potter era explicitamente orientada para o futuro, como sugere o título de seu primeiro livro, no qual considera o desenvolvimento do campo da bioética como um aspecto essencial da sobrevivência humana. Para Whitehouse, os conceitos criados por Potter para explicar sua concepção de bioética são infinitamente mais poderosos que os fatos, mesmo que não tenham granjeado reconhecimento ou sido simplesmente ignorados pela comunidade biomédica norte-americana, marcada pela ideologia de mercado e sem uma filosofia biomédica coerente de base.

Para ilustrar a grande habilidade de Potter em construir palavras para capturar conceitos complexos, Whitehouse relata que durante mais de cinco anos de trabalho conjunto pode observar várias ocasiões nas quais Potter construiu novos conceitos para descrever sua concepção de bioética. Os dois chegaram a cunhar juntos o termo deep bioethics em uma dessas ocasiões, buscando expressar a mistura entre ecologia profunda e Bioética Global:

"Os ecologistas profundos nos pedem para refletir sobre nossas conexões espirituais com o mundo natural, como o fez Leopold, por exemplo, em seu famoso ensaio sobre olhar nos olhos de um lobo agonizante. Portanto, 
existe algo explicitamente espiritual em relação à ética de Potter que exige algum tipo de conexão sagrada aos sistemas naturais, talvez relacionado ao conceito de Wilson, de biofilia. Quando cunhamos o termo 'bioética profunda', tivemos o sentimento de eureka, justamente como Potter descreveu seu estado mental original, ao estar andando de bicicleta, quando teve o insight do termo bioethics" (WHITEHOUSE, Op. cit.).

Whitehouse diz ainda que durante seu trabalho com Potter este também testou o termo priviledge ethics para enfocar os problemas que dividem os povos do mundo entre os que têm acesso aos recursos e à riqueza e os que não têm essa possibilidade de acesso. Relata que Potter também considerou o conceito de bridge ethics para focar a necessidade de conectar diferentes formas de ética médica, ambiental, social e religiosa. Já no final de sua vida trabalhava a perspectiva de desenvolver a noção de uma ética de sustentabilidade da vida humana e qualidade do meio ambiente com um grupo de bioeticistas internacionais, buscando organizar-se para criar um centro de bioética na Universidade de Wisconsin.

Numa visão prospectiva, Whitehouse fala do renascimento da bioética, em termos de ir além das formulações originais de Potter:

"O campo da bioética encontra-se hoje num estágio crítico de evolução, após trinta anos de desenvolvimento de programas de bioética. Encontrase numa fase de profissionalização, respondendo a demandas éticas do contexto clínico e consultoria bioética para a indústria biotecnológica, bem como no nível acadêmico organizacional surgem os primeiros departamentos e programas de doutorado na área" (WHITEHOUSE, Op. cit.).

Contudo, na raiz de todos estes neologismos está a concepção original da própria bioética. O trabalho precursor de Potter preparou o caminho para que a bioética se estabelecesse a partir de uma perspectiva global. Neste sentido, Bridge to the future contém vários insights que são a base para a emergência de uma filosofia científica global que abraça não somente a evolução biológica, mas também acata a diversidade cultural. Assim, a Bioética Global deve ser percebida como uma metáfora que comunica a preocupação para com todo o planeta bem como a abrangência do sistema intelectual.

Embora Potter fosse reconhecido como alguém sempre rápido em apontar que uma ética viável deve estar fundamentada num conhecimento científico de base, o que implica que uma ética global deve ser baseada numa filosofia 
global, foi somente em 1988, quando publicou Global Bioethics: Building on the Leopold Legacy, que seu trabalho ganhou rapidamente a admiração dos europeus, sendo paulatinamente reconhecido também entre os estadunidenses. Este trabalho é inspirado e dedicado a Aldo Leopold, pesquisador da mesma universidade na qual trabalhava (que não chegou a conhecer), que construiu o conceito de land ethics, uma articulação pioneira no ocidente de uma ética do meio ambiente.

Além desses dois colaboradores, que trabalharam diretamente com Potter, consideramos necessário apresentar algumas observações de Warren Reich, sobre a importância de seu trabalho. Para Reich, Potter foi o primeiro a cunhar o termo bioethics em 1970 (REICH, 1995). Embora possamos discutir a respeito de um nascimento em dois lugares, parece claro que Potter cunhou, usou e publicou os termos antes do seu uso pelo Instituto Kennedy de Bioética. Embora seja interessante, a acurada reconstrução histórica feita por esse autor não é tão importante quanto as diferenças fundamentais entre as concepções de bioética de Potter e o que se tornou a forma dominante do pensamento corrente da ética biomédica.

A ética de Potter era inspirada por uma compreensão aguda da biologia, bem como por uma profunda preocupação pessoal em relação à sobrevivência e sustentabilidade da vida no planeta. Embora Potter tivesse explorado as implicações clínicas de seu trabalho na bioética, estava mais preocupado com as relações básicas entre biologia e valores humanos, antes que com aquelas questões levantadas pelos avanços clínicos e científicos da medicina. O interesse de Potter em valores e biologia era prioritário devido seu conhecimento mais especifico da biologia do câncer e implicações do crescimento descontrolado das células e formas de vida em geral. Sua contribuição científica para compreender o metabolismo das células cancerígenas foi fundamental no sentido de capacitá-lo a compreender as complexidades dos sistemas biológicos e sua influência na vida humana. A esse respeito Whitehouse observa:

"É tempo para os bioeticistas levantarem questões mais profundas sobre os objetivos da pesquisa e dos sistemas de saúde. Se considerarmos como um dos objetivos subjacentes da medicina o de promover a sobrevivência da humanidade e a vida no planeta, então o conceito potteriano de bioética merece um renascimento. Isto exigirá sabedoria, não ainda tão evidente em nossos sistemas de saúde. Potter realmente antecipou-se aos tempos ao definir a bioética como sendo uma ponte 
para o futuro, porque sem este pensamento bioético, do qual foi pioneiro, poderemos não ter um futuro" (WHITEHOUSE, Op. cit.).

Se a perspectiva potteriana desde o início era abrangente, tornou-se cada vez mais ampla quando Potter desenvolveu a noção de Bioética Global. Como Reich aponta, o conceito "global" tem vários significados. O primeiro é a idéia que uma bioética precisa abranger as preocupações sobre os diversos ecossistemas e culturas humanas. A bioética de Potter era também intelectualmente ampla e incorporou uma variedade de domínios de deliberação ética, para além daqueles associados com medicina clínica. Porém, talvez a mais importante diferença entre a bioética de Potter e as outras formas de ética biomédica, seja o seu credo pessoal, especialmente porque esse conjunto de valores é vivido concretamente. Para ser um verdadeiro bioeticista, na perspectiva de Potter, é necessário adotar alguns comportamentos e decisões pessoais em relação ao cuidado com o meio ambiente, incluindo o uso dos recursos, o controle populacional e o compromisso com a sustentabilidade do planeta.

Consoante à concepção de Potter, nos parece pertinente alertar para os efeitos devastadores de conflitos de interesse que podem vir a ocorrer se a bioética envolver-se e comprometer-se com questões mercadológicas. O ressurgimento da ética das virtudes pode renovar o interesse na visão de Potter, fortalecendo a idéia de que para alguém ser chamado de bioeticista é imprescindível adotar valores pessoais e comportamento, consistentes com o sistema intelectual de crença por ele desenvolvido.

Nas origens da bioética temos a intuição original Potter e a obra referencial deste campo, que é a Enciclopédia de Bioética. Curiosamente, no curso histórico das origens é a perspectiva de Bioética de Georgetown (bioética médica, clínica) que vai produzir a Enciclopédia de Bioética, a qual praticamente ignorou Potter e sua perspectiva da Bioética Global. Porém, é do encontro destas duas vertentes que nasce a reflexão bioética dos últimos anos e a compreensão que temos hoje de bioética.

Assim, neste resgate histórico fica claro que a reflexão potteriana sobre a bioética se antecipa a toda a problemática ecológica de hoje. Potter, lá nas origens da bioética na década de 1970, se antecipa e aponta para um dos maiores desafios que a humanidade tem neste início de milênio: garantir o futuro da vida no planeta terra. Resgatarmos sua contribuição intelectual para o campo da bioética é uma questão de justiça histórica. 


\section{Referências Bibliográficas}

CONGRESSO MUNDIAL DE BIOÉTICA 4.Van Rensselaer Potter. O Mundo da Saúde. (Vídeo apresentado no IV Congresso Mundial de Bioética Tóquio,4-7 nov 1998) 22 (6): $370-74,1998$.

HARVARDSQUARELIBRAY. Dear Global Bioethics Network. Final Message. Disponível em : http//mcardle.oncology.wisc.edu/faculty/bio/potter_v.html.Acessado em 23 nov 2004. Disponível em: http//www.harvardsquarelibray.org/unitarians/ madison.html. Acessado em 19 nov 2004.

KÜNG, H \& SCHMIDT, H. (Edited by). A global ethic and a global responsibilities. Two Declarations. London: SCM Press Ltd, 1998.

LOWER JR, GM. Van Rensselaer Potter: A memoriam. Cambridge Quarterly of Healthcare Ethics. 11: 329-30, 2002.

MCARDLE. Memorial Resolution of the faculty of the university of WisconsinMadison. On the death of profesor emeritus Van Rensselaer Potter II. Disponível em: http://mcardle.oncology. wisc.edu/faculty/bio/potter_v.html.

MCARDLE. Memorial Resolution of the faculty of the university of WisconsinMadison. On the death of professor emeritus Van Rensselaer Potter II. Faculty Document 1628. Madison 1 april 2002. Disponível em : http:// mcardle.oncology..wisc.edu/faculty/bio/potter_v.html.

POTTER, V.R. Bioethics, bridge to the future. Englewwod Cliffs, N.J.: Prentice-Hall; 1971.

POTTER, V.R. Global Bioethics: building on the Leopold Legacy. East Lansing, Michigan: Michigan State University Press; 1988.

POTTER, V.R. Science, religion must chare quest for global survival. The Scientist 8(10), 1-12, 1994.

REICH, W.T. The word 'bioethics': its birth and the legacies of those who shaped it. Kennedy Institute of Ethics Journal 5(1): 19-34, 1995.

WHITEHOUSE, P.J. In Memoriam. Van Renssselaer Potter: the original bioethicist. Hastings Center Report, nov/dec : 12, 2001.

WHITEHOUSE, P.J. The rebirth of bioethics: extending the original formulations of Van Rensselaer Potter. American Journal of Bioethics 3(4): 26-31, 2003. 